\title{
Impact of common mental disorders on sickness absence in an occupational cohort study
}

\author{
Stephen A Stansfeld, ${ }^{1}$ Rebecca Fuhrer, ${ }^{2}$ Jenny Head ${ }^{3}$
}

${ }^{1}$ Centre for Psychiatry, Wolfson Institute of Preventive Medicine, Barts and the London School of Medicine and Dentistry, London, UK

2Department of Epidemiology, Biostatistics and Occupational Health, McGill University, Montreal, Quebec, Canada ${ }^{3}$ Department of Epidemiology and Public Health, University College London Medical School, London, UK

\section{Correspondence to}

Professor Stephen Stansfeld Centre for Psychiatry, Barts and the London School of Medicine and Dentistry, Old Anatomy Building, Charterhouse Square, London EC1M 6BO, UK: s.a.stansfeld@qmul.ac.uk

Rebecca Fuhrer holds the Canada Research Chair in Psychosocial Epidemiology.

Accepted 11 August 2010 Published Online First 12 December 2010

\section{ABSTRACT}

Objectives Common mental disorders are associated with impaired functioning and sickness absence. We examine whether sub-clinical as well as clinical psychiatric morbidity predict long spells of sickness absence for both psychiatric and non-psychiatric illness. We also examine whether recent common mental disorders and those present on two occasions have a stronger association with sickness absence than less recent and single episodes of disorder.

Methods Common mental disorders measured by the General Health Questionnaire were linked with long spells of sickness absence in 5104 civil servants from the longitudinal Whitehall II Study. Negative binomial models were used to estimate rate ratios for long spells of sickness absence with and without a psychiatric diagnosis (mean follow-up 5.3 years).

Results Clinical but not sub-threshold common mental disorders were associated with increased risk of long spells of psychiatric sickness absence for men, but not for women, after adjusting for covariates (rate ratios (RR) 1.67, 95\% Cl 1.13 to 2.46). Risk of psychiatric sickness absence was associated with recent common mental disorders (RR 2.08, 95\% Cl 1.29 to 3.35) and disorder present on two occasions (RR 1.65, $95 \% \mathrm{Cl} 0.98$ to 2.71 ) for men only. Common mental disorders were not associated with increased risk of non-psychiatric sickness absence after adjustment for covariates.

Conclusions Identification and treatment of common mental disorders may reduce the economic burden of long term psychiatric sickness absence. Our results suggest that public health and clinical services should focus on the identification of workers with elevated mental health symptoms. Studies are needed of the efficacy of early identification and management of mental health symptoms for the prevention of long spells of sickness absence.

\section{INTRODUCTION}

Common mental disorders are associated with impairment of psychological, social and occupational functioning. ${ }^{1-5}$ This has considerable economic impact, partly because common mental disorders also predict all-cause sickness absence, ${ }^{6-12}$ psychiatric sickness absence ${ }^{13} 14$ and disability pension costs. ${ }^{15}$ Sickness absence is a meaningful health outcome for employers and the economy because of lost productivity. Common mental disorders make a substantial contribution to the burden of disease because of the numbers of people affected, $16.4 \%$ in a UK adult population survey. ${ }^{16}$ In cross-sectional studies, dose-response relationships have been found between severity of psychiatric

\section{What this paper adds}

- Common mental disorders predict future sickness absence.

- Less is known about whether the risk is greater for clinical as opposed to sub-clinical disorder or whether this association applies to both psychiatric absence and non-psychiatric absence.

- Clinical but not sub-clinical common mental disorders predict long spells of psychiatric sickness absence in men but not in women.

- Recent common mental disorders are associated with the highest risk of long spells of psychiatric sickness absence in men but not in women.

- Common mental disorders do not predict long spells of non-psychiatric sickness absence.

disorder and level of disability ${ }^{17}$ but there have been few prospective epidemiological studies. ${ }^{18}$ There are also differences by gender and psychiatric diagnosis. Cumulative incidence of sickness absence tends to be higher in women than in men in keeping with higher rates of common mental disorders in women than in men. ${ }^{19} 20$ By contrast, in some studies minor psychiatric morbidity, major depressive disorder, drug abuse/dependence, dysthymia and simple phobia are related to a greater risk of sickness absence in men than in women, ${ }^{8} 21$ although other studies show equal risks of sickness absence associated with common mental disorders in men and women. ${ }^{10}{ }^{11} \mathrm{~A}$ meta-analysis showed a non-significantly decreased risk for psychosocial health and sickness absence in favour of women. ${ }^{22}$ Chronically ill men are also more likely to take longer duration of sickness absence than women. ${ }^{19-21}$

This study examines the association of common mental disorders and long spells of psychiatric and non-psychiatric sickness absence in the longitudinal Whitehall II Study of British Civil Servants. We test whether sub-threshold as well as clinically significant psychiatric morbidity are associated with increased rates of long spells of sickness absence in order to examine whether less severe disorders increase the risk of sickness absence as much as severe disorders. ${ }^{6} 8$ We also examine whether only recent disorder or also less recent disorder increases the risk of long spells of sickness absence and whether disorder on two occasions is associated with greater risk of absence than episodes of disorder on one occasion. 


\section{METHODS}

\section{Participants}

The Whitehall II study was established between 1985 and 1988 with a target population of all male and female civil servants, aged between 35 and 55 years, in 20 London based civil service departments. ${ }^{23}$ With a response rate of $73 \%, 10308$ civil servants were examined in phase 1 of the study (6895 men and 3413 women). We analysed data on common mental disorders from phase 1 and phase 2 (1989, postal questionnaire, response rate $79 \%)$ and phase 3 (1991-1993, questionnaire and screening, response rate $83 \%$ ) of the study together. Sickness absence data including diagnoses were abstracted from civil service records for 1991-1998.

\section{Common mental disorders}

Common mental disorders were measured at phases 1 and 2 using the 30-item General Health Questionnaire (GHO), a well established screening questionnaire for psychiatric disorder. ${ }^{24}$ This was validated against the Clinical Interview Schedule in a sub-sample. ${ }^{25}$ A threshold of $4 / 5$ on the GHO was chosen on the basis of receiver operating characteristic analysis and those scoring $5+$ were deemed 'cases'. At this threshold the sensitivity of the $\mathrm{GHO}$ was $72.7 \%$ and the specificity was $78.0 \%$ against the Clinical Interview Schedule. In order to investigate the impact of sub-threshold scores, we also analysed a three category grouping: no or low scorers, sub-threshold scorers and suprathreshold scorers (caseness) (0-2, 3-4 and 5+). We also studied recurrence and recency of psychiatric morbidity by classifying common mental disorders in terms of caseness at phase 1 or phase 2 only, or caseness at both phase 1 and phase 2 .

\section{Sickness absence}

Ninety-three per cent (9564) of participants gave consent to monitor their sickness absence and of these 96\% (9179) were linked with their civil service record. Computerised sickness absence records to the end of December 1998 were obtained annually. Sickness absence diagnoses were recorded in all departments from 1991 onwards. A medical certificate was required for absences longer than 7 days ('long spells'). Sickness absence diagnoses were coded by the civil service using a coding system based on the $\mathrm{C}$ list of the eighth revision of the International Classification of Diseases (ICD-8). We converted the civil service reason codes to disease categories from the morbidity coding system of the Royal College of General Practitioners (RCGP) which are comparable with ICD-8 chapter headings. We modified the RCGP classification by adding four extra disease categories (gastrointestinal, headache and migraine, neurosis, neurosis ill-defined) that accounted for a high proportion of sickness absence spells. In this paper, we analyse sickness absence during 1 January 1991 to 31 December 1998 for all diagnoses, for psychiatric diagnoses (neurosis and neurosis ill-defined categories combined) and for non-psychiatric diagnoses (all other disease categories combined). Thus, we excluded sickness absence spells in the year immediately after the second measure of common mental disorders in 1989 to ensure that any associations observed were not due to sickness absence taken close to our exposure measure. The validity of civil service reason codes was assessed by obtaining information from participants' general practitioners in $1985-1990 .^{26}$

\section{Covariates}

Socio-economic position was measured by civil service employment grade. Psychosocial work characteristics were measured by the Karasek Job Content Instrument ${ }^{27}$ and questions on effort-reward imbalance. ${ }^{28}$ Three types of perceived social support were measured by the Close Persons Questionnaire. ${ }^{29}$ Social networks were measured by the frequency and number of contacts with relatives, friends and social groups, ${ }^{30}$ and material problems by questions on financial, housing and neighbourhood difficulties. ${ }^{31}$ Other baseline measurements included marital status, units of alcohol consumption per week, self-rated health status over the previous 12 months, recurring health problems in the previous year, and presence of longstanding illness, disability or infirmity. A composite physical illness indicator was created (diabetes, diagnosed heart disease, abnormalities on electrocardiogram, hypertension, respiratory illness and/or angina).

\section{Statistical analysis}

For each participant, we computed the number of long spells of sickness absence and person-years at risk from 1 January 1991 to either 31 December 1998 or date they left the civil service if the participant left during 1991-1998. We fitted negative binomial models to study the association of psychiatric morbidity at phases 1 and 2 with incidence of long spells of sickness absence during 1991-1998. Results are presented as rate ratios. The negative binomial model was used as there was residual variation in excess of the Poisson distribution. Initial models were adjusted for age and employment grade (model 1). Next, models were additionally adjusted for work characteristics, marital status, social support and material problems (model 2). Then, a third model with further adjustment for alcohol consumption and baseline health status was fitted (model 3). We used Stata 9.2 for all analyses.

\section{RESULTS}

Participants were eligible for inclusion based on civil service sickness absence data availability from 1 January 1991 onwards: 6623 participants were eligible (figure 1). There was no difference in prevalence of common mental disorders at baseline in eligible and non-eligible participants (27\% in both). Participants were excluded from our analysis if they had missing data on the GHO at either phase 1 or 2 or any of the covariates: 1519 of the 6623 eligible participants were excluded due to missing data on the GHQ or covariates. The analyses were conducted on 5104 of the original 10308 participants (figure 1).

A quarter of the men and a third of the women were classified as $\mathrm{GHO}$ cases (score of 5 or above) at phase 1 (table 1). In order to increase the discrimination between differing levels of severity of common mental disorders, we distinguished between those scoring $0-2$, those scoring $3-4$ and those scoring 5 or above on the GHQ at phase 1. We also classified common mental disorders in terms of caseness at phase 1 or phase 2 only, or caseness at both phases. The distribution of these scores is set out in table 1 . Notably, $13.4 \%$ of men and $17.7 \%$ of women had common mental disorders at both phases. Over the 8-year sickness absence follow-up (mean follow-up 5.26 years), there were 4046 long spells of sickness absence (2245 in men and 1801 in women). Rates of long spells of absence for psychiatric and non-psychiatric diagnoses are given in table 1 .

$\mathrm{GHO}$ caseness at phase 2 is a risk factor for long spells of psychiatric sickness absence and all-diagnoses sickness absence (1991-1998), adjusting for age and employment grade (table 2). The rate ratios were smaller for non-psychiatric diagnoses sickness absence than for psychiatric sickness absence and were no longer significant after full adjustment. Associations were generally stronger in men than in women. In men, these associations remained significant after additional adjustment for work characteristics, social support, marital status and material 
Figure 1 Description of the sample.

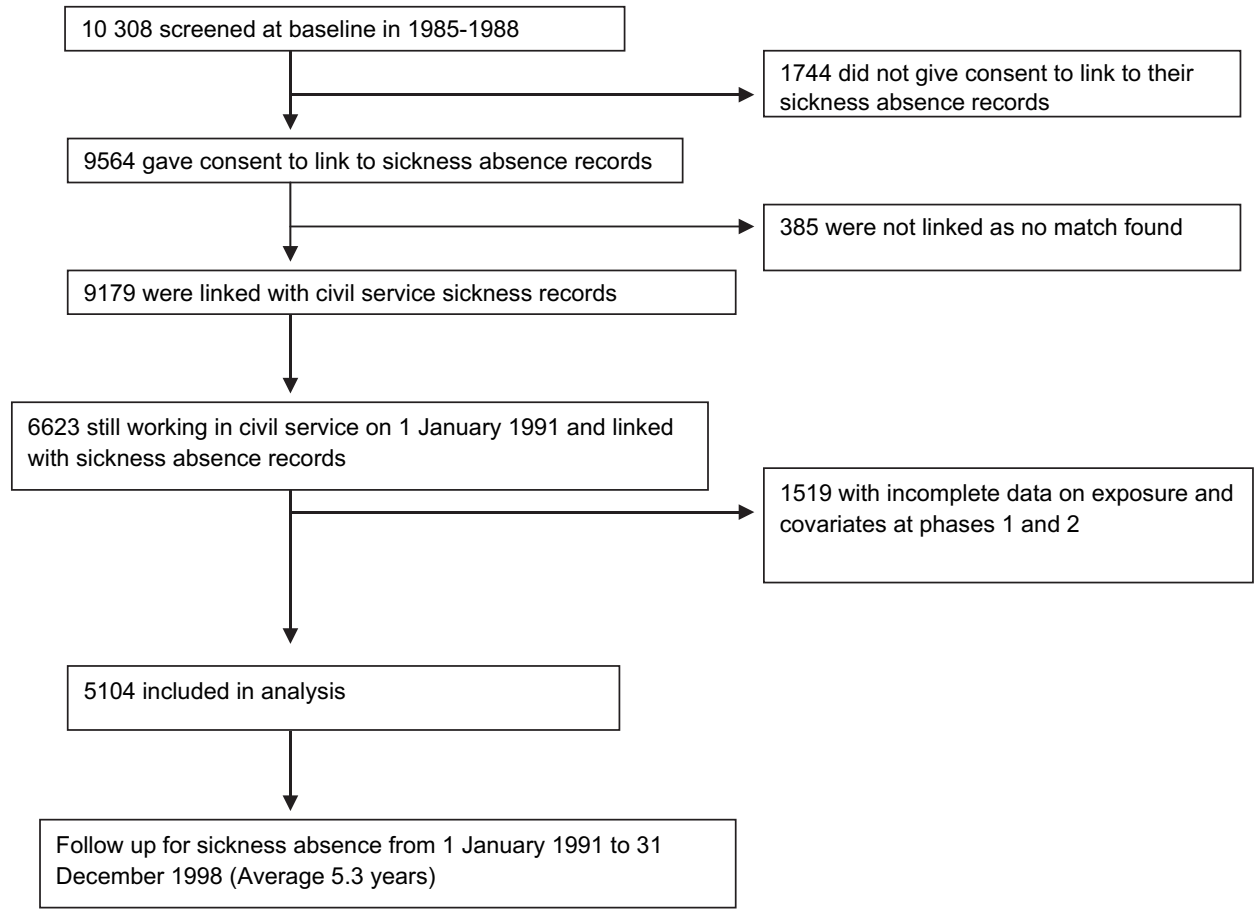

problems (model 2) and for alcohol consumption and physical illness at phase 2 (model 3), although they diminished in magnitude. In women, the associations were no longer significant in model 2. The associations were not significant for sub-threshold common mental disorders in either men or women.

In table 3 we also examined the effects of one and two episodes of common mental disorders on psychiatric, nonpsychiatric and all-diagnoses sickness absence by including common mental disorders at phase 1 and phase 2 as a predictor of future spells of sickness absence between 1991 and 1998. In men, common mental disorders at phase 2 showed increased risk

Table 1 Psychiatric morbidity (GHO) at phases 1 (1985-1988) and 2 (1989-1990), and subsequent long spells of sickness absence (1991-1998) in men and women

\begin{tabular}{|c|c|c|}
\hline & $\begin{array}{l}\text { Men } \\
(n=3638) \\
n(\%)\end{array}$ & $\begin{array}{l}\text { Women } \\
(n=1466) \\
n(\%)\end{array}$ \\
\hline \multicolumn{3}{|l|}{ GHO score at phase 1} \\
\hline $0-2$ & $2350(64.6)$ & $867(59.1)$ \\
\hline $3-4$ & $371(10.2)$ & $152(10.4)$ \\
\hline $5+$ & $917(25.2)$ & $447(30.5)$ \\
\hline \multicolumn{3}{|l|}{ GHO score at phase 2} \\
\hline $0-2$ & $2222(61.1)$ & $817(55.7)$ \\
\hline $3-4$ & $398(10.9)$ & $148(10.1)$ \\
\hline $5+$ & $1018(28.0)$ & $501(34.2)$ \\
\hline \multicolumn{3}{|l|}{ GHO caseness at phases 1 and 2} \\
\hline Neither & $2190(60.2)$ & $778(53.1)$ \\
\hline Phase 1 only & $430(11.8)$ & $187(12.8)$ \\
\hline Phase 2 only & $531(14.6)$ & $241(16.4)$ \\
\hline \multirow[t]{2}{*}{ Phase 1 and phase 2} & $487(13.4)$ & $260(17.7)$ \\
\hline & $\begin{array}{l}\text { Number of spells } \\
\text { (rate per } 100 \\
\text { person-years) }\end{array}$ & $\begin{array}{l}\text { Number of spells } \\
\text { (rate per } 100 \\
\text { person-years) }\end{array}$ \\
\hline Psychiatric long spells, 1991-1998 & $279(1.4)$ & $201(2.7)$ \\
\hline Non-psychiatric long spells, 1991-1998 & $1630(8.3)$ & $1343(18.3)$ \\
\hline Spells with missing diagnosis, 1991-1998 & $336(1.7)$ & $257(3.5)$ \\
\hline All long spells, 1991-1998 & $2245(11.5)$ & $1801(24.6)$ \\
\hline
\end{tabular}

GHO, General Health Questionnaire. for long spells of psychiatric and non-psychiatric sickness absence adjusting for age and employment grade (model 1). The rate ratios were greater in magnitude for psychiatric than for non-psychiatric sickness absence. The magnitude of the risk diminished slightly after further adjustment for work characteristics, social support, marital status and material problems (model 2) and remained significant for psychiatric sickness absence in model 3 but became non-significant for non-psychiatric sickness absence. Associations tended to be weaker or non-significant in women and the pattern was not consistent. In women, common mental disorders at phase 1 , but not at phase 2, were related to long spells of psychiatric sickness absence and these results became non-significant in model 3 .

In general, having common mental disorders at two phases did not increase the risk of psychiatric sickness absence compared to having common mental disorders on one occasion. For men, having common mental disorders at phase 2 only was associated with higher rate ratios for sickness absence than having common mental disorders at both phase 1 and phase 2 . For women, having common mental disorders at two phases was only associated with increased risk of absence in model 1.

\section{DISCUSSION}

Clinical, but not sub-threshold, levels of common mental disorders were associated with increased risk of long spells of psychiatric sickness absence in men; this was also found for all-cause sickness absence in men but not for non-psychiatric sickness absence. Recent common mental disorders were associated with greater risks of long spells of psychiatric sickness absence for men but not for women. Disorder present on two occasions was also associated with increased risk of psychiatric sickness absence in men, but this association was no longer significant after adjustment for alcohol consumption and physical illness. In fully adjusted models, common mental disorders were not associated with increased risk of nonpsychiatric sickness absence. Associations of mental disorder with sickness absence effects were stronger and more consistent for men than for women. 
Table 2 Rate ratios for spells of sickness absence (1991-1998) by psychiatric morbidity (GH0 categories) at phase 2

\begin{tabular}{|c|c|c|c|c|c|c|c|}
\hline \multirow[b]{3}{*}{ Sickness absence } & \multirow{3}{*}{$\begin{array}{l}\text { Phase } 2 \\
\text { GHO score }\end{array}$} & \multicolumn{6}{|l|}{ Rate ratio $(95 \% \mathrm{CI})$} \\
\hline & & \multicolumn{3}{|l|}{$\operatorname{Men}(n=3638)$} & \multicolumn{3}{|l|}{ Women $(n=1466)$} \\
\hline & & Model 1* & Model $2 \nmid$ & Model 3‡ & Model 1* & Model 2† & Model 3‡ \\
\hline \multirow[t]{3}{*}{ Psychiatric long spells } & $0-2$ & 1.0 & 1.0 & 1.0 & 1.0 & 1.0 & 1.0 \\
\hline & $3-4$ & 1.08 (0.58 to 2.03$)$ & $1.02(0.54$ to 1.93$)$ & 0.99 (0.53 to 1.87$)$ & $1.02(0.53$ to 1.95$)$ & 0.94 (0.48 to 1.81$)$ & $0.86(0.45$ to 1.66$)$ \\
\hline & $5+$ & 2.26 (1.57 to 3.25$)$ & 1.95 (1.32 to 2.86$)$ & 1.67 (1.13 to 2.46$)$ & 1.39 (0.93 to 2.09$)$ & 1.15 (0.75 to 1.75$)$ & $1.02(0.66$ to 1.56$)$ \\
\hline \multirow[t]{3}{*}{ Non-psychiatric long spells } & $0-2$ & 1.0 & 1.0 & 1.0 & 1.0 & 1.0 & 1.0 \\
\hline & $3-4$ & 1.10 (0.88 to 1.37$)$ & $1.08(0.86$ to 1.34$)$ & $1.02(0.82$ to 1.27$)$ & $1.16(0.89$ to 1.50$)$ & 1.15 (0.88 to 1.48$)$ & $1.11(0.87$ to 1.43$)$ \\
\hline & $5+$ & $1.31(1.13$ to 1.52$)$ & 1.25 (1.07 to 1.46$)$ & 1.07 (0.92 to 1.25$)$ & 1.09 (0.92 to 1.29$)$ & 1.09 (0.92 to 1.30$)$ & $0.96(0.81$ to 1.14$)$ \\
\hline \multirow[t]{3}{*}{ All diagnoses long spells } & $0-2$ & 1.0 & 1.0 & 1.0 & 1.0 & 1.0 & 1.0 \\
\hline & $3-4$ & $1.16(0.94$ to 1.42$)$ & $1.13(0.92$ to 1.38$)$ & $1.07(0.88$ to 1.31$)$ & $1.16(0.92$ to 1.46$)$ & $1.13(0.90$ to 1.43$)$ & $1.09(0.87$ to 1.36$)$ \\
\hline & $5+$ & 1.48 (1.29 to 1.69$)$ & $1.39(1.20$ to 1.60$)$ & 1.19 (1.03 to 1.37$)$ & $1.15(0.99$ to 1.33$)$ & $1.13(0.96$ to 1.31$)$ & $1.00(0.86$ to 1.17$)$ \\
\hline
\end{tabular}

*Model 1 adjusts for age and employment grade.

†Model 2 adjusts for age, employment grade, work characteristics (decision latitude, job demands, work support, effort-reward imbalance), marital status, social support (confiding/emotional, practical, negative aspects, network outside household) and material problems.

$\ddagger$ Model 3 additionally adjusts for alcohol consumption, self-reported health, health problems in last year, presence of longstanding illness and presence of physical illness.

GHO, General Health Questionnaire.

The strength of this study is the longitudinal data using validated instruments and externally assessed sickness absence in an occupational cohort with a high overall response rate. The results should be generalisable to other white collar public sector organisations, but the findings may apply less to blue collar occupations or the private sector. One weakness is the amount of missing data when all covariates and sickness absence data are used in analyses-possibly a source of bias although prevalence of $\mathrm{GHO}$ caseness at phase 1 was similar in the analysed sample and the full sample with $\mathrm{GHO}$ measured at phase $1(27 \%$ prevalence in both). A further weakness is that diagnosis was missing for just under $15 \%$ of long spells. This is unlikely to have resulted in any major bias. Measurement of common mental disorders relied on a screening questionnaire, the GHO; never- theless, the threshold for $\mathrm{GHO}$ caseness was established in a clinical validation study and concurs well with clinical diagnoses.

Population-based studies also find associations between symptomatic measures of psychiatric disorder and long term sickness absence ${ }^{8-12}$ with one exception that may relate to the sample used in this study. ${ }^{32}$ Few previous studies specifically examine psychiatric sickness absence. Increased risk of sickness absence also tends to be associated with more severe disorder ${ }^{6} 12$ and co-morbid physical disorder. ${ }^{7} 14$ Sub-syndromal psychiatric symptoms have been associated with increased sickness absence risk, ${ }^{69}$ but not in our study. Korten and Henderson ${ }^{33}$ found that the symptoms on the GHO contributed to increased risk of absence even in those without a CIDI diagnosis, suggesting that

Table 3 Rate ratios for spells of sickness absence (1991-1998) by psychiatric morbidity at phases 1 and 2 and both phases

\begin{tabular}{|c|c|c|c|c|c|c|c|}
\hline \multirow[b]{3}{*}{ Sickness absence } & \multirow[b]{3}{*}{ GHO caseness } & \multicolumn{6}{|l|}{ Rate ratio $(95 \% \mathrm{CI})$} \\
\hline & & \multicolumn{3}{|l|}{ Men $(n=3638)$} & \multicolumn{3}{|l|}{ Women $(n=1466)$} \\
\hline & & Model 1* & Model 2† & Model 3‡ & Model 1* & Model 2† & Model 3‡ \\
\hline \multirow[t]{6}{*}{ Psychiatric long spells } & Phase 1 caseness & $1.68(1.16$ to 2.43$)$ & $1.41(0.95$ to 2.10$)$ & $1.22(0.82$ to 1.83$)$ & $1.84(1.24$ to 2.73$)$ & 1.66 (1.10 to 2.51$)$ & $1.43(0.93$ to 2.18$)$ \\
\hline & Phase 2 caseness & 2.24 (1.57 to 3.18$)$ & $1.94(1.34$ to 2.81$)$ & $1.67(1.14$ to 2.43$)$ & $1.39(0.93$ to 2.06$)$ & $1.16(0.77$ to 1.75$)$ & 1.05 (0.69 to 1.58$)$ \\
\hline & Neither & 1.0 & 1.0 & 1.0 & 1.0 & 1.0 & 1.0 \\
\hline & Phase 1 only & $2.03(1.19$ to 3.45$)$ & $1.75(1.01$ to 3.01$)$ & $1.48(0.86$ to 2.57$)$ & $2.49(1.46$ to 4.25$)$ & $2.30(1.34$ to 3.94$)$ & $1.97(1.14$ to 3.40$)$ \\
\hline & Phase 2 only & $2.79(1.76$ to 4.42$)$ & 2.45 (1.52 to 3.93$)$ & $2.08(1.29$ to 3.35$)$ & $1.67(0.97$ to 2.87$)$ & $1.44(0.84$ to 2.49$)$ & $1.34(0.78$ to 2.31$)$ \\
\hline & Both phases & $2.40(1.53$ to 3.81$)$ & 1.99 (1.20 to 3.30$)$ & $1.65(0.98$ to 2.71$)$ & $1.81(1.09$ to 3.01$)$ & $1.49(0.87$ to 2.55$)$ & $1.23(0.70$ to 2.14$)$ \\
\hline \multirow[t]{6}{*}{ Non-psychiatric long spells } & Phase 1 caseness & $1.16(0.99$ to 1.34$)$ & $1.12(0.96$ to 1.31$)$ & $0.92(0.78$ to 1.07$)$ & 1.07 (0.91 to 1.27$)$ & $1.06(0.89$ to 1.26$)$ & 0.91 (0.76 to 1.07$)$ \\
\hline & Phase 2 caseness & $1.29(1.12$ to 1.49$)$ & $1.23(1.06$ to 1.43$)$ & 1.07 (0.92 to 1.24$)$ & $1.06(0.90$ to 1.25$)$ & $1.06(0.90$ to 1.26$)$ & $0.94(0.80$ to 1.11$)$ \\
\hline & Neither & 1.0 & 1.0 & 1.0 & 1.0 & 1.0 & 1.0 \\
\hline & Phase 1 only & 1.12 (0.91 to 1.39$)$ & $1.10(0.89$ to 1.37$)$ & $0.94(0.76$ to 1.17$)$ & 1.10 (0.86 to 1.39$)$ & $1.10(0.87$ to 1.40$)$ & $0.96(0.76$ to 1.21$)$ \\
\hline & Phase 2 only & $1.32(1.09$ to 1.60$)$ & 1.26 (1.04 to 1.53$)$ & $1.15(0.95$ to 1.39$)$ & $1.08(0.87$ to 1.35$)$ & 1.10 (0.88 to 1.37$)$ & $1.01(0.82$ to 1.25$)$ \\
\hline & Both phases & 1.31 (1.08 to 1.58$)$ & $1.25(1.03$ to 1.53$)$ & $0.96(0.78$ to 1.17$)$ & $1.09(0.88$ to 1.34$)$ & $1.07(0.86$ to 1.34$)$ & 0.86 (0.69 to 1.08$)$ \\
\hline \multirow[t]{6}{*}{ All diagnoses long spells } & Phase 1 caseness & $1.27(1.11$ to 1.45$)$ & $1.20(1.04$ to 1.38$)$ & $1.00(0.87$ to 1.15$)$ & 1.18 (1.01 to 1.37$)$ & 1.16 (0.99 to 1.35$)$ & $0.99(0.86$ to 1.16$)$ \\
\hline & Phase 2 caseness & $1.44(1.26$ to 1.65$)$ & 1.36 (1.18 to 1.56$)$ & $1.17(1.02$ to 1.34$)$ & $1.12(0.97$ to 1.30$)$ & 1.10 (0.95 to 1.28$)$ & $0.99(0.85$ to 1.14$)$ \\
\hline & Neither & 1.0 & 1.0 & 1.0 & 1.0 & 1.0 & 1.0 \\
\hline & Phase 1 only & $1.29(1.06$ to 1.57$)$ & $1.25(1.02$ to 1.52$)$ & $1.07(0.89$ to 1.30$)$ & $1.23(1.00$ to 1.52$)$ & $1.24(1.01$ to 1.54$)$ & $1.08(0.88$ to 1.32$)$ \\
\hline & Phase 2 only & $1.54(1.29$ to 1.84$)$ & $1.46(1.22$ to 1.75$)$ & $1.31(1.10$ to 1.56$)$ & $1.14(0.93$ to 1.39$)$ & $1.15(0.94$ to 1.40$)$ & $1.05(0.87$ to 1.27$)$ \\
\hline & Both phases & $1.48(1.24$ to 1.76$)$ & 1.38 (1.15 to 1.66$)$ & 1.07 (0.89 to 1.29$)$ & $1.20(0.99$ to 1.45$)$ & $1.17(0.96$ to 1.42$)$ & $0.96(0.79$ to 1.17$)$ \\
\hline
\end{tabular}

*Model 1 adjusts for age and employment grade.

†Model 2 adjusts for age, employment grade, work characteristics (decision latitude, job demands, work support, effort-reward imbalance), marital status, social support (confiding/emotional, practical, negative aspects, network outside household) and material problems.

$\ddagger$ Model 3 additionally adjusts for alcohol consumption, self-reported health, health problems in last year, presence of longstanding illness and presence of physical illness.

$\mathrm{GHO}$, General Health Questionnaire. 
psychological distress in the absence of clinical diagnosis may be associated with increased absence risk.

We find no increased risk in men with psychiatric disorder for non-psychiatric sickness absence, suggesting that psychiatric disorder does not increase the risk of taking sickness absence for physical illness. However, the increased risk associated with common mental disorders and all-diagnoses sickness absence may indicate increased risk of sickness absence associated with co-morbid psychiatric and physical diagnoses. The latter may reflect the increased risk of developing poorer functioning associated with co-morbidity. ${ }^{14}$ Some studies find stronger associations between psychiatric disorder and sickness absence in men than in women ${ }^{84}$ as we did, but others do not. ${ }^{10} 1233$ The reasons for these gender differences are uncertain. They have been attributed to more effective help seeking in women 83435 leading to earlier treatment and thus less risk of absence from work, but there may be other reasons. One possibility may be that the gender differences are due to a differing propensity to report psychiatric symptoms by gender; that is to say that men scoring above the threshold on the GHO have a more severe psychiatric disorder than women, subsequently associated with higher risk of absence. However, the gender difference in risk of absence has also been found in other studies using interview measures of psychiatric disorder across a range of disorders, some of which had stronger associations with sickness absence in men than in women. ${ }^{8}$ The greater magnitude of the effect in men than women needs to be explained. In women, non-work supports (model 2) and other non-work factors, especially for those working part time, and work support may be more influential in relation to taking absence when psychologically distressed than in men. Furthermore, there may be greater physical comorbidity in women that explains why the rate ratios are much reduced in model 3. Differential health selection out of the cohort, by gender, leaving healthy female workers in the cohort should be considered, but this seems an unlikely explanation because overall rates of absence and psychiatric sickness absence are still higher in women than in men and greater risk of absence associated with psychiatric morbidity is not confined to this cohort alone. ${ }^{8} 34$ Two thirds of the cohort are male and there is no obvious health selection into the cohort by gender; it seems unlikely that men with common mental disorders are more likely to be maintained in employment than women and given the increased rates of all types of sickness absence in women compared to men and given the analyses are based on spells of absence and not duration, increased retention of psychiatrically sicker men seems unlikely.

It is not clear why phase 1 common mental disorders should be more strongly linked to sickness absence in women, while phase 2 morbidity is more strongly linked to sickness absence in men. We find that more severe, recent, and to an extent recurrent, common mental disorders are associated with greatest risk of longer term sickness absence.

Depression has been identified as among the four conditions with the highest overall economic burden in the United States, ${ }^{36}$ and the decline in functioning associated with major depression is equivalent to major physical illnesses. ${ }^{37}$ This has been replicated in major European studies where disability from anxiety disorders and mood disorders was similar to that from heart disease and arthritis. ${ }^{3} 5$ Depression and anxiety have already been identified as prognostic factors for delayed return to work from sickness absence. ${ }^{38}$ Thus identification and treatment of clinically recognisable common mental disorders should be a priority in employed populations in order to try to prevent long term sickness absence and reduce costs. This study suggests that in order to reduce sickness absence the focus should be on conditions of clinical severity rather than milder conditions.

Arising from this study it might proposed that future research should concentrate more on distinguishing the predictors of psychiatric and non-psychiatric sickness absence and exploring the reasons for the gender differences in risk. For prevention there should be more studies examining the effects of modifying working conditions in order to reduce the risk of common mental disorders and hence sickness absence. In terms of reducing the financial burden on organisations, there should be more studies of the efficacy of early identification and management of mental health symptoms to see if this might prevent the development of long spells of sickness absence.

Acknowledgements We thank all participating Civil Service departments and their welfare, personnel and establishment officers, the Occupational Health and Safety Agency, the Council of Civil Service Unions, all participating civil servants in the Whitehall II study and all members of the Whitehall II study team. Michael Marmot who directs the study holds an MRC research professorship and we thank him for his encouragement.

Funding The work presented in this paper was supported by a grant from the Department of Health (grant number 121/5044). The Whitehall II study has been supported by grants from the Medical Research Council, British Heart Foundation, Health and Safety Executive and Department of Health; the US National Heart Lung and Blood Institute (HL36310), National Institute on Ageing (AG13196) and Agency for Health Care Policy Research (HS06516); and the John D and Catherine T MacArthur Foundation Research Networks on Successful Midlife Development and Socio-economic Status and Health.

\section{Competing interests None.}

Ethics approval Ethics approval for the Whitehall II study was obtained from the University College London Medical School committee on the ethics of human research.

Contributors SS designed the study, interpreted the analyses and wrote the first draft of the manuscript. JH carried out the analyses and contributed to the interpretation of the analyses and writing the manuscript. RF interpreted the analyses and contributed to writing the manuscript.

Provenance and peer review Not commissioned; externally peer reviewed.

\section{REFERENCES}

1. Kessler RC, Frank RG. The impact of psychiatric disorders on work loss days Psychol Med 1997;27:861-73.

2. Sanderson K, Andrews G. Prevalence and severity of mental health-related disability and relationship to diagnosis. Psychiatr Serv 2002;53:80-6.

3. Surtees PG, Wainwright NW, Khaw KT, et al. Functional health status, chronic medical conditions and disorders of mood. Br J Psychiatry 2003;183:299-303.

4. Wang PS, Simon G, Kessler RC. The economic burden of depression and the cost-effectiveness of treatment. Int J Methods Psychiatr Res 2003;12:22-33.

5. Buist-Bouwman MA, De Graaf R, Vollebergh WA, et al. ESEMeD/MHEDEA 2000 Investigators. Functional disability of mental disorders and comparison with physica disorders: a study among the general population of six European countries. Acta Psychiatr Scand 2006;113:492-500.

6. Broadhead WE, Blazer DG, George LK, et al. Depression, disability days, and days lost from work in a prospective epidemiologic survey. JAMA 1990;264:2524-8.

7. Hensing G, Spak F, Alexanderson K, et al. Sick-leave among women and the role of psychiatric disorder. Scand J Soc Med 1997;25:185-92.

8. Laitinen-Krispijn S, Bijl RV. Mental disorders and employee sickness absence: the NEMESIS study. Netherlands Mental Health Survey and Incidence Study. Soc Psychiatry Psychiatr Epidemiol 2000;35:71-7.

9. Savikko A, Alexanderson K, Hensing G. Do mental health problems increase sickness absence due to other diseases? Soc Psychiatry Psychiatr Epidemiol 2001;36:310-16.

10. Väänänen A, Toppinen-Tanner $S$, Kalimo $R$, et al. Job characteristics, physical and psychological symptoms, and social support as antecedents of sickness absence among men and women in the private industrial sector. Soc Sci Med 2003:57:807-24

11. Bultmann U, Huibers MJ, van Amelsvoort LP, et al. Psychological distress, fatigue and long-term sickness absence: prospective results from the Maastricht Cohort Study. J Occup Environ Med 2005;47:941-7.

12. Bultmann U, Rugulies R, Lund $T$, et al. Depressive symptoms and the risk of long-term sickness absence: a prospective study among 4747 employees in Denmark. Soc Psychiatry Psychiatr Epidemiol 2006;41:875-80.

13. Henderson M, Glozier N, Holland EK. Long term sickness absence. BMJ 2005;330:802-3. 
14. Buist-Bouwman MA, de Graaf $\mathrm{R}$, Vollebergh WA, et al. Comorbidity of physical and mental disorders and the effect on work-loss days. Acta Psychiatr Scand 2005;111:436-43.

15. Mykletun A, Overland S, Dahl AA, et al. A population-based cohort study of the effect of common mental disorder on disability pension awards. Am J Psychiatry 2006:163:1412-18.

16. Singleton N, Bumpstead R, O'Brien M, et al. Psychiatric morbidity among adults living in private households 2000. London: National Statistics, 2001.

17. Ormel J, VonKorff M, Ustun TB, et al. Common mental disorders and disability across cultures. Results from the WHO Collaborative Study on Psychological Problems in General Health Care. JAMA 1994;272:1741-8.

18. Hensing G, Wahlstrom R. Swedish Council on Technology Assessment in Health Care (SBU). Chapter 7. Sickness absence and psychiatric disorders. Scand J Public Health Supp/ 2004;63:152-80.

19. Hensing G, Brage S, Nygard JF, et al. Sickness absence with psychiatric disorders- an increased risk for marginalization in men? Soc Psychiatr Epidemiol 2000;35:335-40.

20. Hensing G, Andersson L, Brage S. Increase in sickness absence with psychiatric diagnosis in Norway: a general population-based epidemiologic study of age, gender and regional distribution. BMC Med 2006;4:19.

21. Jenkins R. Minor psychiatric morbidity in employed young men and women and its contribution to sickness absence. Br J Ind Med 1985;42:147-54.

22. Duijts SFA, Kant I, Swaen GMH, et al. A meta-analysis of observational studies identifies predictors of sickness absence. J Clin Epidemiol 2007;60:1105-15.

23. Marmot MG, Smith GD, Stansfeld S, et al. Health inequalities among British civil servants: the Whitehall II study. Lancet 1991;337:1387-93.

24. Goldberg D. The detection of Psychiatric IIIness by Questionnaire. Maudsley Monograph No. 21. Oxford: Oxford University Press, 1972.

25. Stansfeld SA, Marmot MG. Social class and minor psychiatric disorder in British Civil Servants: a validated screening survey using the General Health Questionnaire. Psychol Med 1992;22:739-49.

26. Stansfeld S, Feeney A, Head J, et al. Sickness absence for psychiatric illness: the Whitehall II Study. Soc Sci Med 1995;40:189-97.
27. Karasek RA, Theorell T. Healthy work: Stress, productivity and the reconstruction of working life. New York: Basic Books, 1990.

28. Kuper H, Singh-Manoux A, Siegrist J, et al. When reciprocity fails: effort-reward imbalance in relation to coronary heart disease and health functioning within the Whitehall II study. Occup Environ Med 2002;59:777-84.

29. Stansfeld S, Marmot M. Deriving a survey measure of social support: the reliability and validity of the Close Persons Questionnaire. Soc Sci Med 1992;35:1027-35.

30. Berkman LF, Syme SL. Social networks, host resistance, and mortality: a nine-year follow-up study of Alameda County residents. Am J Epidemiol 1979;109:186-204.

31. Pearlin LI. Schooler C.The structure of coping. J Health Soc Behav 1978;19:2-21

32. Andrea H, Beurskens AJ, Metsemakers JF, et al. Health problems and psychosocia work environment as predictors of long term sickness absence in employees who visited the occupational physician and/or general practitioner in relation to work: a prospective study. Occup Environ Med 2003;60:295-300

33. Korten A, Henderson S. The Australian National Survey of Mental Health and WellBeing. Common psychological symptoms and disablement. Br J Psychiatry 2000;177:325-30.

34. Jenkins R. Sex differences in minor psychiatric morbidity: a survey of a homogeneous population. Soc Sci Med 1985;20:887-99.

35. Stansfeld SA, Rael EG, Head J, et al. Social support and psychiatric sickness absence: a prospective study of British civil servants. Psychol Med 1997:27:35-48.

36. Goetzel RZ, Long SR, Ozminkowski RJ, et al. Health, absence, disability, and presenteeism cost estimates of certain physical and mental health conditions affecting U.S. employers. J Occup Environ Med 2004;46:398-412.

37. Wells KB, Stewart A, Hays RD, et al. The functioning and well-being of depressed patients. Results from the Medical Outcomes Study. JAMA 1989;262:914.

38. Nieuwenhuijsen $\mathbf{K}$, Verbeek $\mathbf{J H}$, de Boer AG, et al. Predicting the duration of sickness absence for patients with common mental disorders in occupational health care. Scand J Work Environ Health 2006;32:67-74.

\section{Occupational and Environmental Medicine alerts}

Sign up for our electronic table of contents alerts and you will never miss new issues of Occupational and Environmental Medicine when published online. Stay ahead and up to date by visiting oem.bmj.com. 